\title{
Carbon nanotubes and cyclodextrin polymers for removing organic pollutants from water
}

\author{
K. L. Salipira • B. B. Mamba $\cdot$ R. W. Krause $\cdot$ \\ T. J. Malefetse $\cdot$ S. H. Durbach
}

Received: 26 January 2006 / Accepted: 24 May 2006 / Published online: 16 August 2006

(C) Springer-Verlag 2006

\begin{abstract}
Some organic compounds are major water pollutants. They can be toxic or carcinogenic even at low concentrations. Current technologies, however, fail to remove these contaminants to parts per billion (ppb) levels. Here we report on the removal of organic pollutants from water using cross-linked nanoporous polymers that have been copolymerized with previously functionalized carbon nanotubes. These novel polymers can remove model organic species such as $p$-nitrophenol by as much as $99 \%$ from a $10 \mathrm{mg} / \mathrm{L}$ spiked water sample compared to granular activated carbon and native cyclodextrin polymer that removed only 47 and $58 \%$, respectively. These polymers have also demonstrated the ability to remove trichloroethylene $(10 \mathrm{mg} / \mathrm{L}$ spiked sample) to non-detectable levels (detection limit $<0.01 \mathrm{ppb}$ ) compared to 55 and $70 \%$ for activated carbon and native cyclodextrin polymers, respectively.
\end{abstract}

Keywords Organic pollutants · Polyurethanes · Nanotubes · Functionalization · Polymerization · Absorption

\section{Introduction}

Water is constantly being polluted with organic and inorganic compounds. Domestic and industrial processes discharge these pollutants into the water system (Margiloff 1997) or they are transported by runoff from rain. There are sev-

K. L. Salipira · B. B. Mamba · R. W. Krause $(\bowtie)$.

T. J. Malefetse $\cdot$ S. H. Durbach

Department of Chemical Technology, University of Johannesburg,

P. O. Box 17011, Doornfontein 2028, Johannesburg, South Africa

e-mail: rkrause@uj.ac.za

Tel.: +27-11-406-8074

Fax: +27-11-406-2761 eral types of organic contaminants, such as polychlorinated biphenyls (PCBs), polyaromatic hydrocarbons (PAHs), dioxins, natural organic matter (NOM), endocrine disrupting compounds (EDCs) and dense non-aqueous phase liquids (DNAPLs).

Endocrine disruptors, for example, are dominant in water systems in South Africa and have been highlighted as one of the country's priority organic pollutants. They are chemicals that mimic naturally produced hormones and they interfere with the normal functions and development of organisms (Paris et al. 2006). Endocrine disruptors have also been associated with interrupted sexual behaviour and decreased human semen quality (Richardson 2004; Vidaeff and Sever 2005). Examples of endocrine disruptors include natural and synthetic steroids, sex hormones, some polychlorinated biphenyls and dioxins (Vidaeff and Sever 2005). The European directive of 2001 regards most of the endocrine disruptors as priority contaminants (Richardson 2004).

A number of techniques including activated carbon, zeolites and reverse osmosis are currently being used for water treatment. However, activated carbon fails to remove many organic pollutants to parts per billion levels ( $\mathrm{Li}$ and Ma 1999). Zeolites also show low affinity for organic compounds and reverse osmosis is currently too expensive for widespread use ( $\mathrm{Li}$ and Ma w1999). Thus, an effective, yet economical method to remove these organic pollutants to safe levels is yet to be developed.

Cyclodextrin-polyurethanes containing

carbon nanotubes

Cyclodextrin-based insoluble polymers ( $\mathrm{Li}$ and Ma 1999) have shown a capacity to remove organic species from water at concentration levels as low as parts per trillion levels. In our laboratories, it was found that these polymers could 


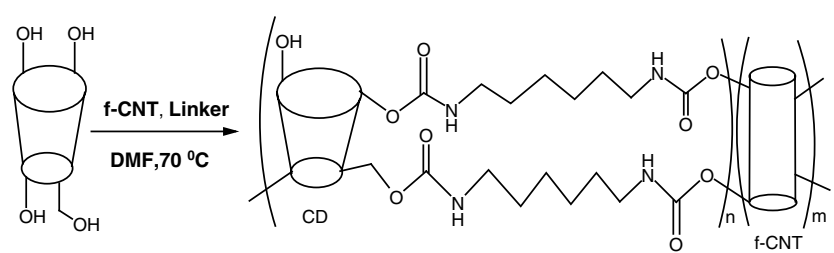

Fig. 1 Polymerization conditions for cyclodextrins and functionalised carbon nanotubes (CD: cyclodextrin; f-CNT: functionalized carbon nanotube; linker: diisocyanate, e.g. hexamethylene diisocyanate, and $m \ll n)$

be recycled at least 18 times while still maintaining their high absorption efficiency. However, the structural integrity of the polymers is somewhat compromised after prolonged recycling. Carbon nanotubes, on the other hand, have shown an ability to efficiently absorb dioxins, polychlorinated dibenzo-furans, biphenyls as reported by Long and Yang (2001), and some inorganic pollutants, but they are currently too expensive on their own to be used for this application.

Cyclodextrin-polyurethanes containing carbon nanotubes polymers consist of a cyclodextrin moiety, a bifunctional linker and a small percentage of functionalized carbon nanotubes. Carbon nanotubes are ideal materials to use in combination with the cyclodextrin polymers because individually they have demonstrated an ability to absorb specific organic molecules while remaining chemically inert. In addition, the strength given to the material by the carbon nanotubes is expected to provide added stability over existing polymers (Ryan et al. 2005; Zhao and Wagner 2004), particularly in improving the recycling and recovery of the material.

In this paper, we present results for the synthesis and characterization of these novel cyclodextrin-based nanoporous polymers containing functionalized carbon nanotubes (Fig. 1). Furthermore, preliminary results of their application in the removal of two selected model organic pollutants from water are discussed.

\section{Experimental}

Polymerization reactions were carried out under inert (argon) conditions. Infrared spectroscopy was done using the MIDAC FT-IR model 4000 and scanning electron microscopy was performed using the JEPL JSM-840 model. The analyses were carried out using a Varian 3800 capillary GC coupled with a Saturn 2000 ion-trap mass spectrometer. The GC was equipped with a Chrompack CP Sil 8 CB, $30 \mathrm{~m}$ $\times 0.25 \mathrm{~mm}$ capillary column with an internal diameter of $0.25 \mu \mathrm{m}$. A modified EPA method '8270' for semi-volatile organics was used for the determination and quantification of the analytes. The chromatographic conditions were $1 \mu \mathrm{L}$ splitless injection at $75^{\circ} \mathrm{C}$ using helium $(\mathrm{He})$ as a carrier gas at $0.9 \mathrm{~cm}^{3} / \mathrm{min}$ constant gas flow. The oven temperature

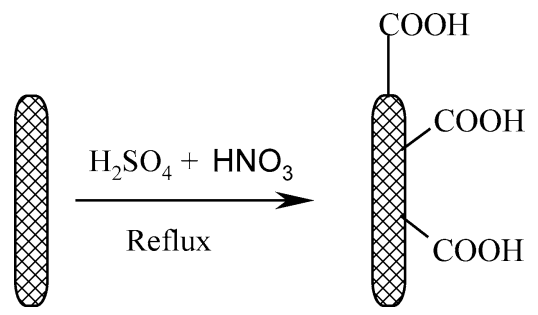

Fig. 2 Functionalization of multiwalled carbon nanotubes

settings were $30^{\circ} \mathrm{C}$ (held for $2 \mathrm{~min}$ ) to $75^{\circ} \mathrm{C}$ at $10^{\circ} \mathrm{C} / \mathrm{min}$, to $100^{\circ} \mathrm{C}$ at $20^{\circ} \mathrm{C} / \mathrm{min}$ (held for $4 \mathrm{~min}$ ). The instrument gave detection limits of $10 \mathrm{ng} / \mathrm{L}$ for the organic contaminants. Cary UV $50 \mathrm{UV}-\mathrm{Vis}$ spectrometer was used to measure absorbances for $p$-nitrophenol at a wavelength of $317.5 \mathrm{~nm}$.

Functionalization of carbon nanotubes

Commercially available multiwalled nanotubes $(1.0 \mathrm{~g})$ produced by chemical vapour deposition of acetylene were oxidized in a mixture of nitric acid $(10 \mathrm{~mL})$ and sulphuric acid $(30 \mathrm{~mL})$ for $30 \mathrm{~min}$ specifically to introduce the carboxylic acid groups (Esumi et al. 1995). The mixture was diluted with distilled water and filtered through Teflon filter paper. The oxidized nanotubes obtained were dried under vacuum at room temperature and characterised by infrared spectroscopy. A model of the functionalized carbon nanotubes is shown in Fig. 2.

Functionalization occurs most readily at defect sites such as bends in the tube, and hence under these conditions carboxylic acid groups are formed on both the tips and the walls of the tubes.

Polymerisation of cyclodextrins with carbon nanotubes

Beta cyclodextrin $(\beta-\mathrm{CD})(1.0 \mathrm{~g})$ was dissolved in dimethyl formamide (DMF) $(18 \mathrm{~mL})$ with stirring. To this solution was added functionalised carbon nanotubes $(0.01$ or $0.02 \mathrm{~g}$ ) previously suspended in DMF $(2 \mathrm{~mL})$. The mixture of the cyclodextrin and carbon nanotubes was then heated to about $70^{\circ} \mathrm{C}$ followed by a drop-wise addition of the bifunctional linker, hexamethylene diisocyanate $(2 \mathrm{~mL})$. This mixture was stirred at $70^{\circ} \mathrm{C}$ under an inert atmosphere for $24 \mathrm{~h}$. The polymer formed was precipitated and washed with acetone in order to remove the residual solvent followed by drying under vacuum at room temperature and the product yield was $75 \%$.

Analysis of $p$-nitrophenol using UV-Vis spectroscopy

Solid phase extraction was carried out in order to determine the amount of pollutant that can be absorbed by the newly synthesized polymer. The extraction was carried out 
Table 1 Physical properties of selected polymers

\begin{tabular}{llllll}
\hline Polymer & Colour & Texture & Yield $(\%)$ & Solubility & Melting point $\left({ }^{\circ} \mathrm{C}\right)$ \\
\hline$\beta \mathrm{CD}-\mathrm{HMDI}$ & White & Mixture of granules and powder & 100 & Insoluble in water and DMF & $217(\mathrm{Dec})$ \\
$1 \% \mathrm{f}-\mathrm{CNT}(\beta \mathrm{CD}-\mathrm{HMDI})$ & Whitish grey & Amorphous, soft with some granules & 75 & Insoluble in water and DMF & $260(\mathrm{Dec})$ \\
$2 \% \mathrm{f}-\mathrm{CNT}(\beta \mathrm{CD}-\mathrm{HMDI})$ & Grey to black & Powdery with few granules & 66 & Insoluble in water and DMF & $277(\mathrm{Dec})$ \\
$3 \% \mathrm{f}-\mathrm{CNT}(\beta \mathrm{CD}-\mathrm{HMDI})$ & Grey to black & Granulated & 70 & Insoluble in water and DMF & $277(\mathrm{Dec})$ \\
$5 \% \mathrm{f}-\mathrm{CNT}(\beta \mathrm{CD}-\mathrm{HMDI})$ & Grey to black & Granulated and soft & 78 & Insoluble in water and DMF & $277(\mathrm{Dec})$ \\
\hline
\end{tabular}

f-CNT: functionalised carbon nanotubes; $\beta \mathrm{CD}$ : beta-cyclodextrin; HMDI: hexamethylene diisocyanate; Dec: decomposition.

using a small column (6 $\mathrm{cm}$ long and $1 \mathrm{~cm}$ in diameter) into which the polymer $(300 \mathrm{mg})$ was packed. The column was conditioned with water $(5 \mathrm{~mL})$ and then a solution of $p$ nitrophenol in water $(30 \mathrm{~mL}, 10 \mathrm{mg} / \mathrm{L})$ was passed through at a flow rate of approximately $3 \mathrm{~mL} / \mathrm{min}$. The eluent was collected and their absorbances were measured using a UV-Vis spectrophotometer.

Analysis of trichloroethylene using gas chromatography - mass spectrometry (GC-MS)

A water sample spiked with trichloroethylene $(30 \mathrm{~mL}$, $10 \mathrm{mg} / \mathrm{L}$ ) was passed through the polymers (300 mg) packed in a small column $(6 \mathrm{~cm}$ long and $1 \mathrm{~cm}$ wide) at a flow rate of about 3-5 $\mathrm{mL} / \mathrm{min}$. The residual trichloroethylene was extracted from the eluent with dichloromethane $(15 \mathrm{~mL})$ using the liquid-liquid extraction technique. One microlitre of the DCM extract was injected into the GC-MS in order to determine the residual trichloroethylene in sample after passing through the polymer. Similarly $1 \mu \mathrm{L}$ of a standard sample solution $(30 \mathrm{~mL}, 10 \mathrm{mg} / \mathrm{L}$ and extracted with DCM (15 mL) but not passed through the polymers was also injected into the GC-MS. The instrumental technique was a modified method for the analysis of semi-volatiles for the Environmental Protection Agency (EPA) 8270.

\section{Results and discussion}

Carbon nanotube functionalization

Carbon nanotubes already have some limited functionality resulting from washing of the nanotubes with acids to remove the catalysts after production. Further functionalization with nitric and sulphuric acid was done specifically to introduce carboxylic acid groups. The nanotubes changed colour from black to dark grey upon functionalization. Examination of the FT-IR spectra of the functionalized carbon nanotubes shows the existence of prominent absorption bands corresponding to $\mathrm{C}-\mathrm{O}\left(1109 \mathrm{~cm}^{-1}\right), \mathrm{C}=\mathrm{O}\left(1700 \mathrm{~cm}^{-1}\right)$ and $\mathrm{O}-\mathrm{H}$ $\left(3434 \mathrm{~cm}^{-1}\right)$. These peaks correspond to the absorbances by carboxylic acid and are in close agreement with observations made by Martinez et al. (2003).
Polymerisation of carbon nanotubes with cyclodextrin using hexamethylene diisocyanate

The polymerisation reaction was monitored by FT-IR spectroscopy and the disappearance of the isocyanate peak at about $2700 \mathrm{~cm}^{-1}$ after $16 \mathrm{~h}$ was observed, an indication that polymerization was complete. The polymers formed showed absorption peaks at $1029,1628,1719$, and $3373 \mathrm{~cm}^{-1}$ suggesting the presence of $\mathrm{C}-\mathrm{N}, \mathrm{C}=\mathrm{C}, \mathrm{C}=\mathrm{O}$ and $\mathrm{O}-\mathrm{H}$ bonds, respectively. Table 1 shows the physical properties of some of the polymers that were prepared. The synthesized polymers are generally insoluble in water and organic solvents, and were obtained in quantitative yields. It is noteworthy that the polymers posses a high thermal stability after incorporation of carbon nanotubes. The table further demonstrates the variation in physical properties of the polymers and highlights the significant increase in thermal stability after adding a small amount of nanotubes.

Preliminary tests of carbon nanotube-based cyclodextrin polymers with $p$-nitrophenol

$p$-Nitrophenol was chosen as a model pollutant because it is one of the priority pollutants that can easily be monitored by UV-Vis spectroscopy. It has also been used in our laboratory before as model pollutant in similar systems. According to UV-Vis results, polymers that contain carbon nanotubes are more efficient than the native $\mathrm{CD}$ polymers or granular activated carbon (GAC) at the absorption of PNP. The absorption efficiency of these polymers is illustrated in Table 2 .

Table 2 highlights the increased absorption efficiency of the polymers containing the functionalised nanotubes.

Analysis of the synthesised polymers by scanning electron microscope showed that the surface was porous and resembles a sponge. It has also been observed that the CNT$\beta C D$ polymers that were soft and whose surface was porous had an enhanced absorption of our model pollutant (PNP) compared to those that were hard.

When taking into account the $\mathrm{sp}^{2}$ hybridization of carbon atoms of carbon nanotubes of the phenyl carbons of the pollutant, there is a high likelihood of $\pi-\pi$ interactions resulting from $\pi$-stacking. As a result this may lead to an 
Table 2 Percent $p$-nitrophenol absorbed by polymers

\begin{tabular}{lllll}
\hline Sample ID & Mass $(\mathrm{g})$ & $\begin{array}{l}\text { Initial concentration } \\
(\mathrm{mg} / \mathrm{L})\end{array}$ & $\begin{array}{l}\text { Final concentration } \\
(\mathrm{mg} / \mathrm{L})\end{array}$ & $\begin{array}{l}p \text {-Nitro phenol absorbed } \\
(\%)\end{array}$ \\
\hline GAC & 0.3 & 10 & 5.30 & 47 \\
$\beta$ CD-HMDI & 0.3 & 10 & 4.20 & 58 \\
$1 \% \mathrm{f}-\mathrm{CNT}(\beta \mathrm{CD}-\mathrm{HMDI})$ & 0.3 & 10 & 0.07 & 99 \\
2\% f-CNT $(\beta$ CD-HMDI $)$ & 0.3 & 10 & 0.83 & 92 \\
$3 \% \mathrm{f}-\mathrm{CNT}(\beta \mathrm{CD}-\mathrm{HMDI})$ & 0.3 & 10 & 0.80 & 92 \\
5\% f-CNT $(\beta$ CD-HMDI $)$ & 0.3 & 10 & 0.30 & 97 \\
\hline
\end{tabular}

GAC: granular activated carbon; $\beta \mathrm{CD}$ : beta-cyclodextrin; HMDI: hexamethylene diisocyanate; f-CNT: functionalised carbon nanotubes.

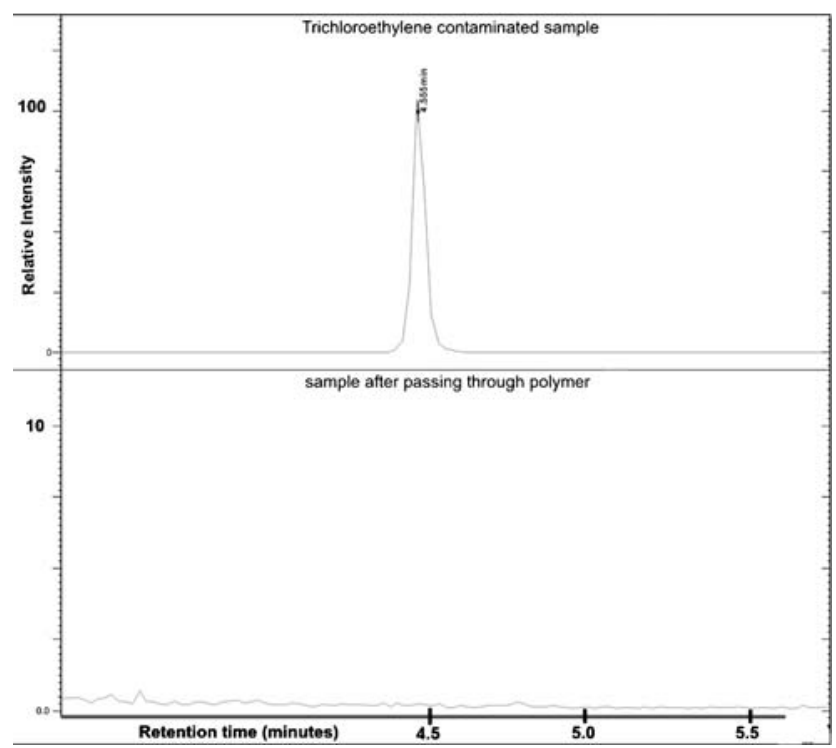

Fig. 3 GC/MS chromatographs of trichloroethylene (TCE) spiked water sample before and after passing through the polymer. GC/MS: gas chromatography-mass spectrometry

attraction between carbon nanotubes and $p$-nitrophenol. Calculations of the binding energy constants to this effect are still in progress. Furthermore, the added factor that carbon nanotubes can absorb organic species would also account for the high absorption efficiencies observed compared to the native polymer.

Gas chromatography - mass spectrometry (GC-MS) analysis for trichloroethylene absorption

The GC-MS experiments were performed in water samples where the concentration of the trichloroethylene pollutant is $10 \mathrm{mg} / \mathrm{L}$. Trichloroethylene is one priority pollutants found in many South African river water systems and other groundwater sources world-wide. Since it is also an endocrine disrupting compound (EDC), it was a very useful model test pollutant. While the native cyclodextrin polymers demonstrated a good absorption efficiency $(>80 \%)$ for the pollutant, the polymers incorporated with carbon nanotubes performed even better. Shown in Fig. 3 are chromatogram where a $5 \% \mathrm{CNT}(\beta$-CD) polymer completely absorbed the trichloroethylene species at an efficiency greater than $99 \%$.

The gas chromatograms presented in Fig. 3 show the combined total ion current for the $m / z=130+131+132$ ions. There is no detectable TCE (bottom trace) after passing the sample through the polymers.

\section{Conclusion}

We demonstrated that polymerisation of cyclodextrins with functionalised carbon nanotubes is possible and that the resultant polymers have an enhanced absorption capacity for $p$-nitrophenol compared to activated carbon and native cyclodextrin polymers. GC-MS results have also demonstrated the ability of these polymers in the absorption of trichloroethylene from water at concentration loads of parts per million. It has also been observed that surface properties of a polymer are probably an important factor in determining the extent to which the polymer could absorb the organic pollutants from water. Surface area analysis experiments are currently underway. Research to produce more novel carbon nanotube - cyclodextrin polymers and the testing of these polymers for the removal of other pollutants including dioxins, PCBs and DNAPLs at parts per billion levels is being pursued. Carbon nanotubes from different sources and produced by different methods are being considered in our current polymerization studies.

Acknowledgements Funding from the University of Johannesburg, National Research Foundation (NRF), the Water Research Commission (WRC) and Tertiary Education Support Program (TESP) (ESKOM) is gratefully acknowledged.

\section{References}

Esumi K, Ishigami M, Nakajima A, Sawada K, Honda H (1995) Chemical treatment of carbon nanotubes. Carbon 34(2):279-281

Li DQ, Ma M (1999) Nanosponges: from inclusion chemistry to water purifying technology. Chemtech 35:31-37

Long R, Yang R (2001) Carbon nanotubes as superior sorbent for dioxin removal. J Am Chem Soc 123:2058 
Martinez MT, Callejas MA, Benoit M, Cochet M, Seeger T, Anson A, Schreiber J, Gordon C, Marhic C, Chauvet O, Fierro JLG, Maser WK (2003) Sensitivity of single wall carbon nanotubes to oxidative processing: structure modification, intercalation and functionalization. Carbon 41(12):2247-2256

Margiloff IB (1997) Chem Eng Proc 93:10

Paris F, Jeandel C, Servant N (2006) Increased serum estrogenic bioactivity in three male newborns with ambiguous genitalia: a potential consequence of parental exposure to environmental endocrine disruptors. Environ Res 100:39-43

Richardson DRS (2004) Environmental mass spectrometry: Emerging contaminants and current issues. Anal Chem 76:3337-3362
Ryan KP, Cadek M, Nicolosi V, Walker S, Ruether M, Fonseca A, Nagy JB, Blau WJ, Coleman JN (2005) Multiwall carbon nanaotube nucleated crystallization and reinforcement in poly(vinyl alcohol). Synmet 11769-11773

Vidaeff AC, Sever LE (2005) In utero exposure to environmental estrogens and male reproductive health: a systematic review of biological and epidemiologic evidence. Reprod Toxicol 20:5-20

Zhao Q, Wagner HD (2004) Raman spectroscopy of carbon nanotube cyclodextrin-base polymers. Phil Trans R Soc Lond A 362:24072424 